\title{
Development of a Tribally-led Gardening Curriculum for Indigenous Preschool Children: The FRESH Study
}

\author{
Marianna S. Wetherill, PhD, MPH, RDN/LD ${ }^{1}$; Emily E. Bourque, RDN/LD ${ }^{2, \dagger}$; \\ Tori Taniguchi, $\mathrm{MPH}^{3}$; Charlotte V. Love, $\mathrm{MPH}^{3, \ddagger}$; Margaret Sisk, $\mathrm{AFA}^{4}$; \\ Valarie Blue Bird Jernigan, DrPH, $\mathrm{MPH}^{3}$
}

\section{INTRODUCTION}

Early childhood is a sensitive period for healthy weight development and is an important determinant of obesity risk across the life course. ${ }^{1,2}$ Thus, early childhood is a critical window for obesity prevention, ${ }^{3}$ with particular opportunity for reducing Indigenous American Indian (AI) disparities. ${ }^{4}$ By the age of 2 years, the average AI child will weigh more than their White peer, and this excess weight usually persists into kindergarten. ${ }^{3}$ Disparities are particularly pervasive within rural AI communities. ${ }^{5}$

The causes of AI obesity disparities are multifactorial, which has important implications for early childhood obesity prevention programs in tribal communities. Political, structural, and economic pathways influence community food access, learned food preferences, and loss of traditional foodways. ${ }^{6}$ Nationally, 1 out of 4 AI households experience food insecurity, ${ }^{7}$ with many tribal communities reporting even higher rates. $^{8-10}$
American Indian families with children are disproportionately affected by food insecurity ${ }^{10}$ and commonly report poor access to fresh fruits and vegetables and a heavy reliance on energy-dense, commodity foods to feed their families. ${ }^{11}$ Although studies are limited, poor food access may contribute to obesity disparities among AI adults, ${ }^{8}$ and may also negatively influence fruit and vegetable food preferences among AI families with young children. ${ }^{10}$ The Indigenous food sovereignty movement is a grassroots community organizing movement that emphasizes the mobilization of tribal resources to reclaim food systems. ${ }^{12}$ It promotes active participation in food harvesting at the individual, family, community, and regional levels as a strategy to protect cultural heritage, promote health, and ensure food security. ${ }^{13}$

Early childcare and education centers (ECEs) are long-recognized as an important environmental influence on learned eating behaviors. Several ECE obesity programs have

\footnotetext{
${ }^{1}$ Department of Health Promotion Sciences, Hudson College of Public Health, University of Oklahoma Health Sciences Center, Tulsa, OK

${ }^{2}$ Private Practice Dietitian, Tampa, FL

${ }^{3}$ School of Health Care Administration, Oklahoma State University Center for Health Sciences, Tulsa, OK

${ }^{4}$ Osage Nation, Harvest Land, Pawhuska, OK

${ }^{\dagger}$ Emily E. Bourque was affiliated with the University of Oklahoma Health Sciences Dietetic Internship program at the time the study was completed.

${ }^{\ddagger}$ Charlotte V. Love was affiliated with the Center for Indigenous Health Research and Policy, Oklahoma State University, Center for Health Sciences at the time the study was completed. Conflict of Interest Disclosure: The authors have not stated any conflicts of interest.

Address for correspondence: Marianna S. Wetherill, PhD, MPH, RDN/LD, University of Oklahoma, Tulsa Schusterman Center, College of Public Health, 4502 E 41st St, Tulsa, OK 74135; E-mail: marianna-wetherill@ouhsc.edu

J Nutr Educ Behav. 2021;53:991-995

(C) 2021 The Authors. Published by Elsevier Inc. on behalf of Society for Nutrition Education and Behavior. This is an open access article under the CC BY-NC-ND license (http:// creativecommons.org/licenses/by-nc-nd/4.0/)

https://doi.org/10.1016/j.jneb.2021.07.011
}

been successfully implemented in urban schools, ${ }^{14,15}$ many serving Hispanic and Black youth. However, little information is available for rural AI communities, in which tribes often operate their own ECEs. Implemented in tribal ECEs, the Food Resource Equity and Sustainability for Health (FRESH) study aimed to improve vegetable intake, food security, and body composition of preschool-aged children and their families. Consisting of child, parent, and ECE environmental interventions, this longitudinal randomized control study was designed to advance Indigenous food sovereignty within the Osage Nation, a rural reservation community in Oklahoma. This study describes the processes used to develop, implement, and evaluate the preschool curriculum component designed to increase children's exposure to vegetables as a pathway toward learned food preferences for these foods.

Food Resource Equity and Sustainability for Health Study Overview

The FRESH study used a communitybased participatory research process that involved Osage Nation tribal leaders from the early childhood education and agricultural sectors in every aspect of the research, from the development of the research questions and study implementation to the data collection, analysis, and dissemination of the findings. As 1 element of a multicomponent intervention for ECE families, the FRESH preschool curriculum was accompanied by a school menu best practices redesign $^{16}$ and a supplemental teacher training on responsive feeding practices ${ }^{17}$ described elsewhere. Intervention ECE school menus 
incorporated local, fresh, and culturally tailored foods from the tribe's newly launched farm. A complimentary, parent-focused, 16-week hybrid curriculum was delivered via a combination of weekly online learning modules and monthly in-person family nights. These family nights featured Indigenous foods and food sovereignty activities to promote community awareness and collective efficacy for a more equitable and sustainable tribal food system. All participating families included 1 or more members who self-identified as AI. The FRESH study was approved by the Oklahoma State University Center for Health Sciences Institutional Review Board.

\section{Participatory Adaptation of the FRESH Preschool Curriculum}

We adapted the FRESH preschool curriculum through a series of meetings with Osage leadership and teachers over 6 months. Members of the academic team completed tours of the schools, discussed existing curricula with teachers, and reviewed preexisting school-based gardening curricula. As an outcome of these early meetings, the FRESH preschool curriculum was ultimately informed by 2 preexisting preschool-gardening curricula. First piloted in New Hampshire, the original Early Sprouts curriculum spans 24-weeks through 6-week cycles to illustrate the 4 growing seasons, with each weekly cycle featuring 1 of 6 target vegetables. ${ }^{18}$ This curriculum was the primary source for the adapted FRESH preschool curriculum. Piloted in North Carolina, Watch Me Grow ${ }^{19}$ involved a crop-a-month structured curriculum spanning 4 months. We added elements from this second curriculum to supplement the teacher's manual, primarily classroom discussion questions and introductory reading activities.

Before developing the FRESH preschool curriculum, 2 members of the research team reviewed the Early Sprouts implementation resource manual (E.E.B. and M.S.W.), ${ }^{18}$ and 1 member who led the adaptation completed the corresponding 10-hour online training program (E.E.B.). The FRESH preschool curriculum preserved fidelity to Early Sprouts by retaining a combination of sensory exploration, gardening, classroom cooking, and take-home recipe kits to promote family involvement. All of these activities are theoretically designed to help young children overcome innate neophobia for vegetables. In our discussions with teachers, we prioritized maintaining fidelity to the intervention and focused on making adaptations when necessary in the delivery of the intervention rather than core elements of the content. For example, we discussed the availability and comfort level of teachers in conducting selected gardening activities that supported the curricula delivery and what supports needed to be in place for the teachers to successfully implement the curricula. Additional factors, including vegetable cost and regional availability in this reservation setting, were also an important consideration, and ultimately the FRESH preschool curriculum was adapted to span 15weeks through 3 5-week cycles (Explore, Sprout, and Harvest).

The primary adaptations included replacement of swiss chard with spinach and green beans with butter (lima) beans while retaining tomatoes, bell peppers, carrots, and butternut squash target vegetables from the original Early Sprouts curriculum. Butter beans and squash were combined into a single weekly module to introduce children to Three Sisters, a traditional Indigenous approach for growing these 2 crops with corn. $^{20}$ Inspired by Watch Me Grow, ${ }^{19}$ we added an introductory activity (eg, book or song) for the first 5 weeks to introduce the children to the vegetable of the week in an engaging and interactive way, including discussion questions for teachers before, during, and after each reading. A unique storytelling activity included an introduction to Three Sisters. ${ }^{20}$ In addition, 5 of the 15 recipes for in-class preparation and take-home kits were modified to integrate spinach and butter beans and simplified cooking methods. Recipes were taste-tested among a sample of teachers before finalization. Esteemed tribal elders fluent in the Osage language contributed translations for the names of target vegetables (eg, Doocazn is carrot) and other gardening terms (eg, o4 $\mathrm{a}$ is garden). See Supplementary Data for a summary of adaptations and translated words.

\section{Teacher Training and Classroom Implementation}

Before implementation, all teachers received a 3-hour training in July 2017 on the beta version of the adapted preschool curriculum, including a step-by-step manual, which also provided 1 final opportunity for teacher feedback. An essential part of the training prioritized importance of fostering a student's willingness to try over the actual eating of vegetables. This was achieved by training teachers to role model willingness to try and to encourage students less willing to try vegetables to explore with their other senses (sight, feel, smell, sound). Example teacher response scripts for reluctant students were included for teacher reference. Teachers were also trained to ask the question of whether or not each student liked the vegetable a lot, a little, or not yet ${ }^{18}$ on the conclusion of each weekly sensory and cooking activity.

The teacher's manual also included supplemental information with each lesson (eg, pictures identifying the parts of vegetable plants and basic nutrition information) to support teacher confidence in curriculum implementation regardless of their background. The final written curriculum was later distributed to all participating classrooms in January 2018 during a recap training delivered to 38 teachers and aids immediately before implementation. Curriculum implementation boxes were also provided to create a classroom environment that stimulated food learning. Example items included vegetable-themed toys, chef-dress-up costumes, and items required for teaching specific activities, such as vegetable-themed books, magnifying glasses, and child gardening supplies. Each week, classrooms were provided with food ingredients needed to complete sensory and inclassroom cooking activities and prepared take-home kits for children to prepare each week's recipe again at home with their families. During the 
study's intervention phase (January and May 2018), 13 classrooms implemented the curriculum across 5 ECE sites owned and operated by the Osage Nation (2-4 classrooms per site). Because the curriculum involved outdoor gardening activities, demonstration gardens were built for each participating ECE site.

\section{Evaluation}

On concluding each weekly lesson, teachers completed an implementation survey to evaluate fidelity to the preschool curriculum and how it was received by teachers and students. Overall implementation each week was high across all 15 weeks. All classrooms reported completing each weekly reading activity during the first 5 weeks. Completion of sensory activities ranged from $100 \%$ to $84.6 \%$, and completion of cooking activities ranged from $100 \%$ to $76.9 \%$ across classrooms (Table 1 ).

Teachers were also asked to provide written, open-ended feedback each week about the real-world implementation of the project (Figure 1). Thematic review of qualitative survey responses indicated that children particularly enjoyed activities involving cutting with the knives and cutting boards and mystery bags (paper bags that contained the weekly vegetable). Teachers organically wove FRESH curricula together with other lessons, including repurposing a fruit can as a pen holder to demonstrate repurposing and hanging aprons on the clothesline to dry as part of lessons about clothing. Noted challenges included the need for 2 teachers to help implement lessons and sometimes not having adequate time to prepare for the lesson or deliver the full lesson. Classroom cooking plans were sometimes altered, including asking the school cook to prepare the recipe for student tasting, or students prepared the recipe but did not get to taste the final product in the classroom. Areas for improvement included a need for more flexibility with the curriculum (eg, shorter lessons or being able to split activities into smaller components). Teachers suggested the use of time-lapse videos of plants growing.

\section{Lessons Learned and Program Sustainability Within the Food Sovereignty Movement}

Evaluation of the FRESH curriculum indicates it can be implemented successfully in ECE classrooms, so long as adequate support is provided to teachers. Flexibility in delivering the curriculum proved essential, especially for the multiage ECE classroom setting. Tailoring the curriculum to local AI cultural traditions supported community interest and participation in the program, as demonstrated by families sharing photographs of themselves preparing their takehome meal kits. Future curriculum refinements could include modifications to lesson plans to allow for flexibility in weekly implementation and provision of preportioned classroom recipe kits for easier preparation in the classroom by teachers and students. The impact of the curriculum on food security, vegetable intake, and body composition will be described in a forthcoming manuscript.

Since its original implementation, the FRESH Children's Gardens and classroom curriculum have become an integral component within ECE settings within the Osage Nation. To optimize the use of raised bed growing space, vegetables have since been modified through school cook and teacher input. The current planting design includes tomatoes, potatoes, bell peppers, and onions for spring planting and radishes, spinach, beets, and mixed lettuce for fall planting.

Table. Process Evaluation Results for the FRESH Curriculum ( $n=13$ Classrooms)

Introductory Reading Sensory Activity ${ }^{a}$ Cooking Activity

Week
1
2
3
4
5
6
7
8
9
10
11
12
13
14
15
$\%$ Activity Completion (No. Classrooms)

$\begin{array}{lcc}100 & 100 & 100 \\ 100 & 100 & 100 \\ 100 & 100 & 100 \\ 100 & 100 & 84.6(11) \\ 100 & 84.6(11) & 92.3(12) \\ - & 100 & 84.6(11) \\ - & 92.3(12) & 92.3(12) \\ - & 100 & 100 \\ - & 92.3(12) & 76.9(10) \\ - & 100 & 100 \\ - & 100 & 100 \\ - & 100 & 92.3(12) \\ - & 92.3(12) & 92.3(12) \\ - & 91.7(12) & 91.7(11) \\ - & 100 & 100\end{array}$

Overall Class Response to Recipe Taste ${ }^{b, c}$

Enjoyed or Neutral (No. Classrooms)

100

FRESH indicates Food Resource Equity and Sustainability for Health.

${ }^{a}$ For weeks 11-15, completion of sensory activities includes indoor, outdoor, or both; ${ }^{\mathrm{b}}$ Teacher observed assessment of children's overall liking of the recipe. Originally measured as overall enjoyed, neutral, mixed, or disliked. Percent reported represents enjoyed and neutral combined; ' Percentages are adjusted for classrooms that completed the cooking activity.

$69.2(9)$
$38.5(5)$
$69.2(9)$
$45.5(5)$
$61.5(8)$
$81.2(9)$
$41.7(5)$
$61.5(8)$
$60.0(6)$
$76.9(10)$
$76.9(10)$
$54.5(6)$
$50.0(6)$
$72.7(8)$
$76.9(10)$




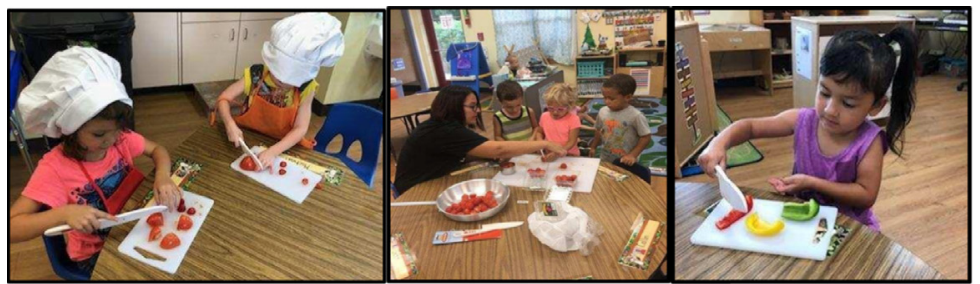

"The children really enjoy cutting with the knives and cutting boards." -Fairfax Head Start preschool teacher

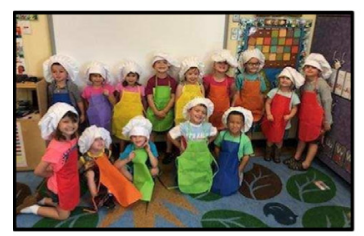

"I made a clothesline on the fence of the playground with a piece of yarn and after washing the aprons, I had each student hang their own apron and when they were dry the students had to take their apron off the clothesline, fold the apron, and put it away. This allowed for real life experience for our classroom curriculum."

-Pawhuska language immersion teacher

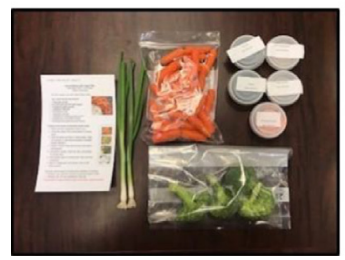

"I think the cooking activities should be just the same and as easy as takehome recipe kits. The take home kits are easier to cook and also to clean up. That's exactly how it needs to be in the classrooms."

-Pawhuska language immersion teacher

Figure. Qualitative examples of curriculum implementation and teacher feedback. Photograph Credit: Osage Nation Communications Department.

Harvested produce is first used by ECE school kitchens, and excess produce is distributed through the Elder Nutrition Program to Osage elders as part of a broadening effort to foster tribal resilience and community health. The Osage Nation has incorporated lessons from this study into a new and expanded Community Supported Agriculture program that will be launched in the near future and provide farm produce weekly to more AI families across the Osage Nation. Collectively, this food knowledge, production, and access initiatives support the goal of creating a more food secure, food sovereign tribal nation.

\section{NOTES}

The study was approved by the Institutional Review Board of Oklahoma State University Center for Health Sciences and funded by the National Institutes on Minority Health and Health Disparities (5R01MD01126603). The Osage Nation congress provided study oversight and tribal approval of the study. The contents of this publication are solely the authors' responsibility and do not necessarily represent the official views of the National Heart, Lung, and Blood
Institute or the National Institutes of Health. The funding agency did not participate in the study design, data collection, analysis, decision to publish, or manuscript preparation.

The authors would like to acknowledge and thank the members of the FRESH Study Executive Committee and all who participated in the project, too numerous to mention, but including Assistant Chief Raymond RedCorn, David Webb, Michelle Harding, Melvina Prather, Denise Keene, Dana Daylight, Helen Brumley, Shane Rencountre, Margaret Sisk, Jason George, and Jann Hayman. The authors would also like to thank Ms Gail Boe for her leadership in initiating preliminary intervention work. The authors thank Robynn Rulo for her leadership in implementing this study within the schools. Finally, the authors thank all study participants for their time, knowledge shared, and continued commitment to their children's health and well-being.

\section{SUPPLEMENTARY DATA}

Supplementary data related to this article can be found at https://doi. org/10.1016/j.jneb.2021.07.011.

\section{REFERENCES}

1. Dixon B, Peña MM, Taveras EM. Lifecourse approach to racial/ethnic disparities in childhood obesity. Adv Nutr (Bethesda, MD). 2012;3:73-82.

2. Lucas A. Programming by early nutrition in man. In: Bock G, Whelan J, eds. The Childhood Environment and Adult Disease, John Wiley \& Sons; 1991:38-55.

3. Isong IA, Richmond T, Avendaño M, Kawachi I. Racial/ethnic disparities: a longitudinal study of growth trajectories among US kindergarten children. J Racial Ethn Health Disparities. 2018;5:875-884.

4. Schell LM, Gallo MV. Overweight and obesity among North American Indian infants, children, and youth. Am J Hum Biol Off $J$ Hum Biol Counc. 2012;24:302-313.

5. James CV, Moonesinghe R, WilsonFrederick SM, Hall JE, Penman-Aguilar A, Bouye K. Racial/ethnic health disparities among rural adults United States, 2012-2015. MMWR Surveill Summ. 2017;66:1-9.

6. Jernigan VB, Salvatore AL, Styne DM, Winkleby M. Addressing food insecurity in a Native American reservation using community-based participatory research. Health Educ Res. 2012;27:645-655.

7. Jernigan VBB, Huyser KR, Valdes J, Simonds VW. Food insecurity among 
American Indians and Alaska natives: a national profile using the current population survey-food security supplement. $J$ Hunger Environ Nutr. 2017;12:1-10.

8. Jernigan VBB, Wetherill MS, Hearod J, et al. Food insecurity and chronic diseases among American Indians in Rural Oklahoma: the THRIVE study. Am J Public Health. 2017;107:441-446.

9. Sowerwine J, Mucioki M, Sarna-Wojcicki D, Hillman L. Reframing food security by and for Native American communities: a case study among tribes in the Klamath River basin of Oregon and California. Food Sec. 2019;11:579607.

10. Bauer KW, Widome R, Himes JH, et al. High food insecurity and its correlates among families living on a rural American Indian reservation. Am J Public Health. 2012;102:1346-1352.

11. Finegold K. Background Report on the Use and Impact of Food Assistance Programs on Indian Reservations (No. 4). US Department of Agriculture, Economic Research Service; 2005
12. Jernigan VBB. Health and social issues of Native American women. In: Joe JR, Gachupin FC, eds. Addressing Food Security and Food Sovereignty in Native American Communities, Praeger; 2012:113-132.

13. Indigenous Food Systems Network. Indigenous food sovereignty. https:// www.indigenousfoodsystems.org/ food-sovereignty. Accessed July 7 , 2020.

14. Yin Z, Parra-Medina D, Cordova A, et al. Míranos! Look at us, we are healthy! An environmental approach to early childhood obesity prevention. Child Obes. 2012;8:429-439.

15. Natale RA, Messiah SE, Asfour LS, Uhlhorn SB, Englebert NE, Arheart KL. Obesity prevention program in childcare centers: two-year follow-up. Am J Health Promot. 2017;31(6):502510.

16. Sisson SB, Sleet K, Rickman R, Love C, Williams M, Jernigan VBB. The development of child and adult care food program best-practice menu and training for Native American head start programs: the FRESH study. Prev Med Rep. 2019;14:100880.

17. Sleet K, Sisson SB, Dev DA, et al. The impact of responsive feeding practice training on teacher feeding behaviors in tribal early care and education: the food resource equity and sustainability for health (FRESH) study. Curr Dev Nutr. 2019;4:23-32.

18. Kalich K, Bauer D, McPartlin D. Early Sprouts: Cultivating Healthy Food Choices in Young Children. Redleaf Press; 2009.

19. Namenek Brouwer RJ, Benjamin Neelon SE. Watch Me Grow: a garden-based pilot intervention to increase vegetable and fruit intake in preschoolers. BMC Public Health. 2013;13:363.

20. Pleasant Mt J. Food yields and nutrient analyses of the three Sisters: a Haudenosaunee cropping system. Ethnobiol Lett. 2016;7:87-98.

\section{ORCID}

Marianna S. Wetherill: http://orcid. org/0000-0002-5937-4686

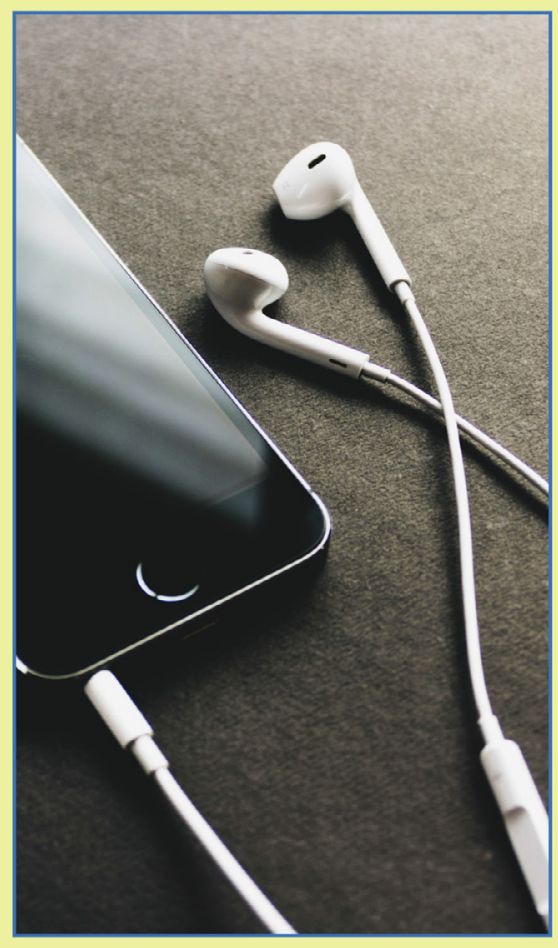

In case you missed it...

A podcast is available online at www.jneb.org.

\section{Examination of Factors That Contribute to Breastfeeding Disparities and Inequities for Black Women in the US}
M. Petit, D. A. Smart, V. Sattler, N. K. Wood 